\title{
Treatability of a used Lube Oil from Contaminated Soil
}

\author{
Geetha Das, M.S.Revathy, Gangadhara Angajala, B.Sundaravel
}

\begin{abstract}
The oily petroleum hydrocarbon discharge lead to the soil pollution, become harmful to both human being and the environment by long run. This present work is carried out systematically to evaluate the efficiency of Brij-35 for washing used lubricant oil. For this study, the soil and waste engine oil which was collected from local service station are characterized. The soil under study was categorized through soil gradient test. The permeability of the soil was also determined. The soil fraction which was obtained by sieving through $\mathrm{mm}$ sieve was used for the present analysis. All the characteristic properties of the soil and oil were tested by a prescribed method. The used lube oil density was $0.853 \mathrm{gm} / \mathrm{cc}$ at $15^{\circ} \mathrm{C}$. The interfacial tension of the oil under study was $52.1 \mathrm{mN} / \mathrm{m}$. This important finding helpful in finding the solution for soil contamination by improper disposal of oily hydrocarbon wastes like waste lube oil.
\end{abstract}

Keywords : Soil remediation, Waste oil treatment, Mass percentage.

\section{INTRODUCTION}

\section{A. Waste lube oil- The soil pollutant}

Lubricating oil is the petroleum fraction which is used in almost all machineries and vehicles for decreasing rubbing between surfaces in moving parts. During its application, it undergoes oxidation and generated most impurities in base oil. This spent oil is known as waste engine oil. Used lube oil (ULO) is the petroleum based synthetic spent oil and become unsuitable for its original purpose as it is subjected to high temperature and mechanical strain during running of the vehicle for stipulated time [1]. It is a brown to black color liquid mixture consisting of low to high molecular weight $\left(\mathrm{C}_{16^{-}} \mathrm{C}_{36}\right)$ aliphatic and aromatic hydrocarbons viz polychlorinated biphenyl, chloro dibenzofurans, alkylbenzenes, naphthalene, methylnaphthalenes, lubricative additives and decomposition products along with heavy metal contaminants such as zinc, antimony, Iron, lead and chromium[2-3]. Because of its structural stability, the degradation becomes challenge in such cases.

Revised Manuscript Received on December 05, 2019

* Correspondence Author

D.Geetha*, Chemistry, Kalasalingam Academy of Research and Education, Krishnankoil, Virudhunagar, India.

Email: geethachem2015@gmail.com

M.S.Revathy, Physics, Kalasalingam Academy of Research and Education, Krishnankoil, Virudhunagar, India.

Email: revz.vijay@gmail.com

Gangadhara Angajala, Chemistry, Kalasalingam Academy of Research and Education, Krishnankoil, Virudhunagar, India.

Email: gangadharaangajala@gmail.com

B.Sundaravel, Chemistry, Kalasalingam Academy of Research and Education, Krishnankoil, Virudhunagar, India.

Email: sundar.chem.bala@gmail.com
Thus, they are more dangerous anthropogenic pollutant and they have carcinogenic, less biodegradable mechanical impurities [4]. Used lubricant oil, causes environmental problem mainly due to the following reason [4]:

- Source has no Ineffective monitoring and control of their sources.

- Poor environmental monitoring of recycling.

In some cases such as in passenger cars, the used oil was collected by the servicing companies whereas, in the case of agricultural machines like tractors the oil service need to be done on the spot. Taking into consideration the fact that used oils are considered to be hazardous and extremely toxic waste, their transfer strategies viz. arrive filling, street oiling, dump on the ground diminishes soil efficiency for production of food and for age [5].

\section{B. Trends of lube oil in India}

Used lube oil is indeed harmful to the environment, but also has some recovery value. As per the Hazardous Waste (Management, Handling and Transboundary Movement) Rules, 2008 (HW Rules) any waste which by reason of any of its physical, chemical, reactive, toxic, flammable, explosive or corrosive characteristics causes danger or is likely to cause danger to health or environment, whether alone or when in contact with other wastes or substances are hazardous. As per Schedule IV of the Hazardous Waste Rules, 2008, both used oil \& waste oil have been categorized as 'hazardous wastes' and also listed in Schedule I under the rules[6].

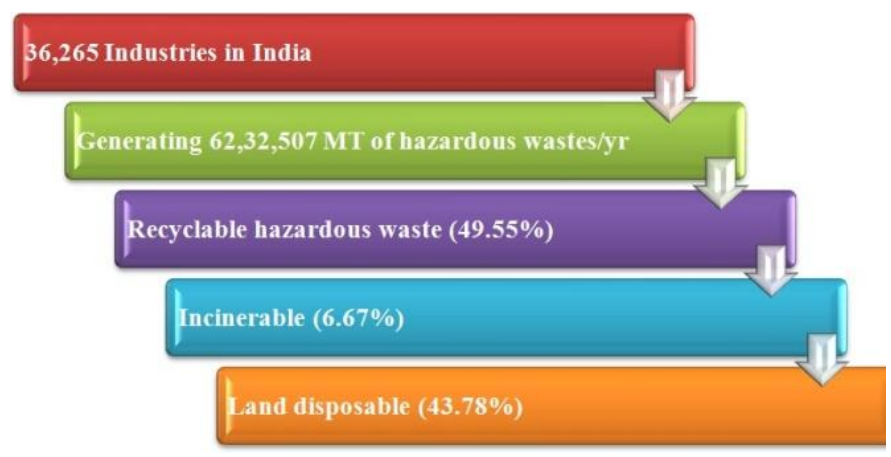

Fig. 1. Quantum of recyclable waste generated in India [1].

India has a huge recycling potential with a significant amount of recyclable waste generated. Particularly, there are about 257 Spent oil (Used/Waste Oil) registered recycling facilities distributed across 124 districts spread over 19 states in India with the total spent oil recycling capacity as1.39 MMT [6].

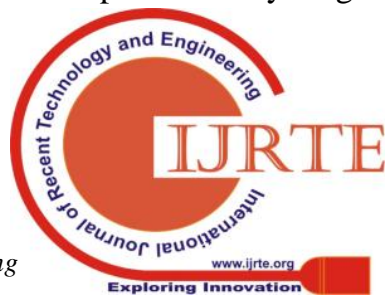




\section{MATERIALS AND METHODS}

There is enormous potential in utilizing such wastes thereby conserving rapidly depleting natural resources, increasing employment, and reducing environmental degradation. The major constraint faced in recycling waste is cost of the collection, storage \& subsequent transportation of the waste to the recycling unit. On the other hand, the development of bio lubricants facing constraints as they are 1.5 and 5 times more expensive than conventional lubricants. In order to get the balance between economical and environmental balance, reprocessing of waste would be the best choice. Hence there is huge scope for reprocessing of used/waste oil sector in India at present.

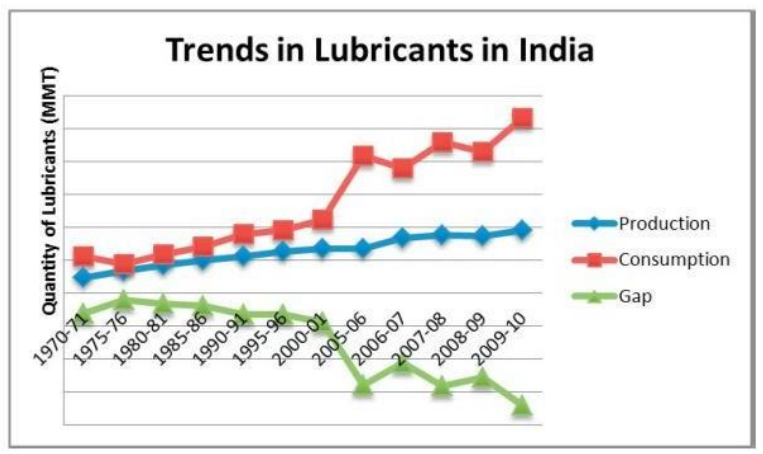

Fig. 2. Lubricants trends in India [1,4]

\section{Surfactant treatment on ULO}

The global trend is run after the green technologies in order to face the shortcomings of the top major environmental issues. Numerous researches have been undergoing particularly for recycling the waste lube oil [1]. Various surfactants have been intensively studied for evaluating their efficiencies for the treatment of used lube oil [7, 8]. The waste lube oil spillage into the soil contaminates and leads to the water pollution and in long run clog the aquifers and contaminate the ground water [9]. The surfactant enhanced soil washing have already been used as an efficient technology for removal of soil contamination particularly with poly aromatic hydrocarbon (PAH).

\section{Background and objectives}

The rise of green economy and intensification of global energy crisis have been gaining attention of researchers and accelerating the research on recycling the waste oil in large scale. Even though, small scale and pilot scale low technologies can not contribute much to the needed large scale high technology recycling, the joint efforts of various recycling technologies may bring forth alternate oil resources and reduction of environmental pollution as well. In this platform, the present study aims to know the efficiency of Brij-35 surfactant solution in removing waste lube oil from contaminated soil. The collected soil sample was characterized by soil gradient analysis and specific gravity, permeability, bulk densities were measured. The density, viscosity and surface tension of the waste engine oil were also measured before the washing of the contaminated soil with surfactant.

\section{A. Materials}

Used lubricant oil collected from local auto mobile workshop nearby Sivakasi, Tamil Nadu. Soil under study was collected from Kalasalingam University campus, Krishnan Koil, Tamil Nadu. The soil was artificially contaminated with waste engine oil. To simulate soil contamination by waste engine oil, the sandy material was first saturated with water and drained to residual water saturation, then restarted with oil and drained to residual oil saturation. The residual oil in the drained sand occupied approximately $23 \%$ of the soil pore space $(23 \%$ saturation approximately $0.0477 \mathrm{~g}$ per gram of soil) [4]. N-Hexane, commercial grade nonionic surfactant dodecyl alcohol ether (Brij-35) was purchased from Merck and used as received.

\section{B. Methods for soil characterization \\ - Sieve analysis}

The fraction which was passing through a $0.6 \mathrm{~mm}$ sieve was used in the experiment after air drying. The soil sample which was collected is a medium to fine sand and categorized through soil gradient curve. The average hydraulic conductivity of the soil is $4 \times 10^{-3} \mathrm{~cm} / \mathrm{s}$. The physic-chemical properties are listed in Table1.

\section{- $\quad$ Specific gravity}

The density bottle is washed with water and then washed with alcohol. Finally, washed with ether to remove alcohol. Weight of the empty bottle with stopper is $\left(\mathrm{W}_{1}\right)$.

About 20gm of soil sample which is cooled in desiccators is transferred to the bottle. $\mathrm{W}_{2}$ is the weight of the bottle and soil. $10 \mathrm{ml}$ of distilled water is put in the bottle and allowed the soil to soak completely. After 2 hours again the bottle is completely filled with distilled water with stopper kept under constant temperature in water baths. The bottle is taken outside, dried, and weighed asW (The $_{3}$ weight of the bottle and the contents). Then empty bottle is cleaned thoroughly. That weight is $\mathrm{W}_{4}$ at temperature.

\section{- Permeability test}

The permeability of soil was analyzed through constant head method as well as falling head method.

\section{- Bulk density}

Height of the cylindrical vessel in measured and then weight is taken. The vessel is filled with sand upto $2 / 3$ height and again weighed. The sand is transferred to the mixing pan, $2 \%$ of water is added and mixed well. The most sand is transferred to the cylinder and the height is noted down from the top. With the increase of the percentage of water, the weight is noted down from the top till the height from the top is equal to the original height. The graph is drawn between the mixture content and percentage increase in bulk.

\section{B. Methods for ULO characterization \\ - Viscosity of ULO}

The Saybolt viscometer is used to determine the viscosity. The apparatus consists of an oil container surrounded by water container including stirrer and electric heater, underneath of collecting flask a valve cork provided to operate the capillary. Two thermometers are fitted 
respectively in the oil and water container.

\section{- Oil removal efficiency of the surfactant}

The aqueous solutions of Brij-35 surfactant at various concentrations were used to wash the contaminated soil material, which had been contaminated with residual level of ULO.

For these studies, $5 \mathrm{~g}$ of contaminated soil was added to 100 $\mathrm{ml}$ surfactant solution (1:30 solid to solution ratio) in a beaker and stirred on a magnetic stirrer for 24 hours at 28 ${ }^{\circ} \mathrm{C}$. The sample was allowed for settling. The supernatant solution was decanted after 8 hours settling, and then the beaker with soil was first rinsed once with $50 \mathrm{ml}$ surfactant solution, and then twice with $50 \mathrm{ml}$ water. First rinse was to remove oil that became attached to the inside of the beaker during decanting of the supernatant and the second rinse with water were to wash the surfactant solution from the soil since it can interfere with the quantification of oil contaminant. The oil which remained on the soil was determined by the partition gravimetric using extraction methods [4]. The contaminated soil was extracted with 30.0 $\mathrm{ml}$ of $\mathrm{n}$-hexane and the extract filtered through a whatman filter paper then transferred into a petri dish. After evaporating $n$-hexane, the weight of the dish was taken and the amount of oil was quantified.

\section{RESULTS AND DISCUSSION}

\section{A. Soil characterization}

- Sieve analysis by soil gradient

The material that would have been retained on pan during sieve analysis is equal to the total mass of soil taken for dry sieve analysis minus the sum of the masses of material retained on all sieves. The graph was drawn and the grain size distribution curve for the soil in a semi-logarithmic graph is obtained and given in Fig. 1 and the results are tabulated in Table- I. The specific gravity of the soil is 2.96 . The results of the permeability test are listed in Table- II \& III. The average permeability is calculated as follows:

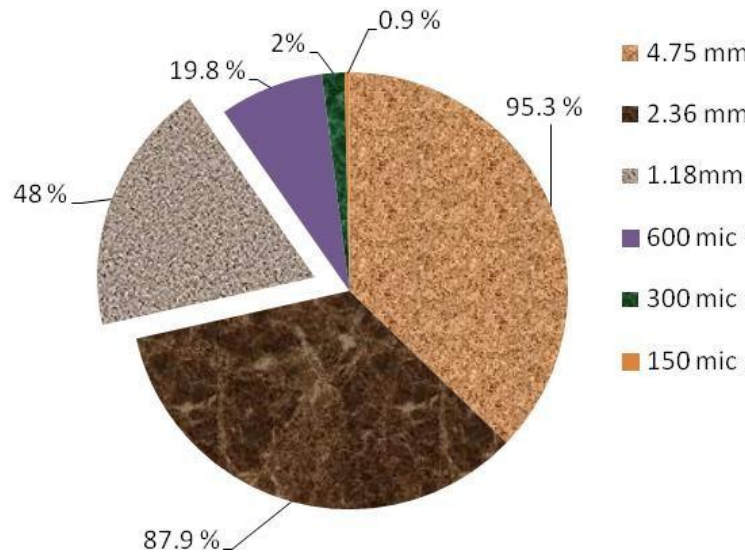

Fig. 3. Soil fraction obtained by soil gradient analysis.

Table- I. Various Soil Fractions obtained by Soil Gradient Analysis

\begin{tabular}{|c|c|c|r|c|}
\hline $\begin{array}{c}\text { Is.ieve } \\
\text { No. }\end{array}$ & $\begin{array}{c}\text { Wt } \\
\text { retained } \\
\text { in g.ms. }\end{array}$ & $\begin{array}{c}\text { cumulative } \\
\text { wt retained }\end{array}$ & $\begin{array}{c}\text { cumulat } \\
\text { ive wt } \\
\text { retained }\end{array}$ & $\begin{array}{c}\% \\
\text { finer }\end{array}$ \\
\hline $4.75 \mathrm{~mm}$ & 47 & 47 & 4.7 & 95.3 \\
\hline $2.36 \mathrm{~mm}$ & 74 & 121 & 12.1 & 87.9 \\
\hline $1.18 \mathrm{~mm}$ & 399 & 520 & 52.0 & 48.0 \\
\hline $600 \mathrm{mic}$ & 282 & 802 & 80.2 & 19.8 \\
\hline $300 \mathrm{mic}$ & 155 & 957 & 95.7 & 4.3 \\
\hline $150 \mathrm{mic}$ & 34 & 991 & 99.1 & 0.9 \\
\hline Pan & 9 & 1000 & 100.0 & 0 \\
\hline
\end{tabular}

Table- II. Results of permeability test by constant head method.

\begin{tabular}{|c|c|c|c|}
\hline $\begin{array}{c}\text { Height of } \\
\text { Water } \\
(\mathbf{H})\end{array}$ & $\begin{array}{c}\text { time in } \\
\text { sec } \\
\text { (T) }\end{array}$ & $\begin{array}{c}\text { Amount of } \\
\text { Water } \\
\text { (A) }\end{array}$ & $K=2 L / T A H$ \\
\hline 60 & 30 & 215 & 0.0225 \\
\hline 60 & 60 & 360 & 0.0188 \\
\hline 60 & 90 & 570 & 0.0199 \\
\hline 60 & 120 & 750 & 0.0196 \\
\hline 60 & 150 & 970 & 0.0203 \\
\cline { 3 - 4 } & & & $\mathrm{k}=0.06072 \mathrm{~cm} / \mathrm{sec}$. \\
\hline
\end{tabular}

Table- III. Average permeability of the soil by falling head method.

\begin{tabular}{|c|c|c|c|}
\hline Initial & Final & Time in sec & ${\text { Permeability } \mathbf{~ k}^{*}}^{*}$ \\
\hline 60 & 50 & 60 & 0.0210 \\
\hline 50 & 40 & 67 & 0.0228 \\
\hline 40 & 30 & 72 & 0.0275 \\
\hline 30 & 20 & 90 & 0.0311 \\
\hline 20 & 10 & 120 & 0.0400 \\
\hline \multicolumn{3}{|c}{$*\left[2.302 \mathrm{H} * \log _{10}\left(h_{1} / h_{2}\right)\right.$} \\
\hline
\end{tabular}

- $\quad$ Bulk density

Bulk density is the weight of soil in a given volume. As per literatures, soils with a bulk density higher than $1.6 \mathrm{~g} / \mathrm{cm}^{3}$ become more compact and restrict root growth. Permeability is the ability of a soil to allow passage of water through the medium. Understanding permeability gives an idea about the structure of the soil and how water passes through different layers. Soil has a layered structure moreover water pressure at the surface would not be same at the middle portion. Determination of permeability is an important one to study fluid-flow characteristics through a soil mass and thus helps in improving workability of the soil. The infiltration capacity of the soil will get reduced if its permeability and bulk density is higher.

Table IV. Properties of the Soil

\begin{tabular}{|c|c|}
\hline Soil properties & Values \\
\hline Texture & Medium to fine sand \\
\hline Particle density & $2.9 \mathrm{~g} / \mathrm{cm}^{3}$ \\
\hline Bulk density & $0.572 \mathrm{~g} / \mathrm{cm}^{3}(1.28)^{*}$ \\
\hline Hydraulic conductivity & $4 \times 10^{-3} \mathrm{~cm} / \mathrm{s}\left(2 * 10^{-3}\right)^{*}$ \\
\hline
\end{tabular}




\begin{tabular}{|c|c|}
\hline $\mathrm{pH}$ & $7-8$ \\
\hline $\begin{array}{c}\text { Permeability(Constant head } \\
\text { method) }\end{array}$ & 0.06072 \\
\hline $\begin{array}{c}\text { Permeability (Falling head } \\
\text { method) }\end{array}$ & 0.07798 \\
\hline
\end{tabular}

* Values after contamination

\section{- Characterization of ULO}

The density, viscosity and the interfacial tension (IFT) of the oil under study have been considered as the very important fluid properties as they determine rate of product recovery and migration of oil. These properties were analyzed and given in Table- IV.

As per the results given in the Table- IV, the waste engine oil has lower density i.e., 0.867. Thus the oil tends to accumulate above the water table region since its density is lower than that of the water. It is considered that, the density varies with temperature but as per the literatures, in most of the subsurface environments the temperature remains relatively constant. The viscosity and interfacial tension values of the oil give knowledge about the easiness of recovery. The oil with lower viscosity relatively has higher mobility than that of the thick oil of relatively higher viscosity. The interfacial tension of the oil determines the wettability of the oil. In general, higher the IFT, higher is the capillary pressure and greater the stability of the interface, which is responsible for higher residual saturation. The interfacial tension for completely miscible liquids is 0 dyne $\mathrm{cm}^{-1}$ and the surface tension of water is 72 $\mathrm{mN} / \mathrm{m}$ at $25^{\circ} \mathrm{C}[9]$. Thus, the IFT of the oil under study fall between these two extremes i.e., $52.1 \mathrm{mN} / \mathrm{m}$.

Table- V: Physico Chemical Properties of used Lubricant Oil

\begin{tabular}{|l|l|l|}
\hline Test Parameters & Test Method & Results \\
\hline Density $\left(15^{\circ} \mathrm{C}\right)$ & IS 1448 Part 32 & $0.853 \mathrm{gm} / \mathrm{cc}$ \\
\hline $\begin{array}{l}\text { Kinematic } \\
\text { viscosity }(40 \circ \mathrm{C})\end{array}$ & IS 1448 Part 25 & $82.9 \mathrm{cSt}$ \\
\hline $\begin{array}{l}\text { Flash point } \\
(\text { Cleveland open- cup) }\end{array}$ & IS 1448) Part 69 & $220{ }^{\circ} \mathrm{C}$ \\
\hline Water content & $\begin{array}{l}\text { IS 2362 (Instrument } \\
\text { used - Karl fisher titrator) }\end{array}$ & $0.1 \%(\mathrm{w} / \mathrm{w})$ \\
\hline $\begin{array}{l}\text { Gross calorific } \\
\text { value }\end{array}$ & ASTM D 240 & $8.44 \mathrm{kcal} / \mathrm{g}$ \\
\hline Ash Content & IS1448 Part 4 & $0.07 \%(\mathrm{w} / \mathrm{w})$ \\
\hline & $\begin{array}{l}\text { Instrument } \\
\text { used(ICP-OES)-Inductive } \\
\text { coupled } \\
\text { optical } \\
\text { spectrometer }\end{array}$ & $\begin{array}{l}\text { Less than } 0.1 \\
\mathrm{mg} / \mathrm{kg}\end{array}$ \\
\hline
\end{tabular}

Table- VI: Viscosity variation with Temperature.

\begin{tabular}{|c|c|c|c|}
\hline $\begin{array}{c}\text { Temperature } \\
\text { of Oil }\left({ }^{\circ} \mathbf{C}\right)\end{array}$ & $\begin{array}{c}\text { Time taken } \\
\text { for 40 } \mathbf{~ m l} \\
\text { collection } \\
(\mathbf{s e c})\end{array}$ & $\begin{array}{c}\text { Kinematic } \\
\text { viscosity } \\
\text { (centistokes) }\end{array}$ & $\begin{array}{c}\text { Absolu } \\
\text { te } \\
\text { viscosit } \\
\mathbf{y} \\
\left(\mathbf{N s} / \mathbf{m}^{\mathbf{2}}\right)\end{array}$ \\
\hline 40 & 228 & 58.01 & 5.512 \\
41 & 218 & 56.06 & 5.012 \\
42 & 206 & 52.09 & 4.654 \\
\hline
\end{tabular}

The preferred surfactant concentrations for washing were fixed above its critical micelle concentration $(\mathrm{CMC}=0.09$ $\mathrm{mM}$ for Brij 35). The mass percentage of oil which was removed from the soil samples by surfactant washing are depicted in Fig. 2. The washing ability of the surfactantincreased with increase of their concentration, thus increased solubility. As a result, the potential removal of trapped waste-lubricant oil droplets in the surfactant micelle gets increased. Below CMC, the surfactant present as single molecule [9]. After CMC, the surfactant molecule started to form micelles. The micelles solubilize more amount of waste engine oil by trapping them into its hydrophobiccore.

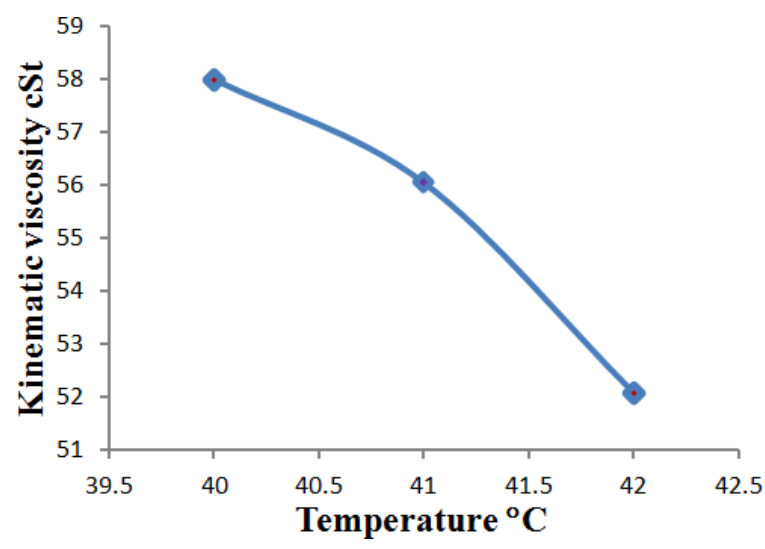

Fig. 4. Change of viscosity with temperature.

- Batch washing of oil contaminant

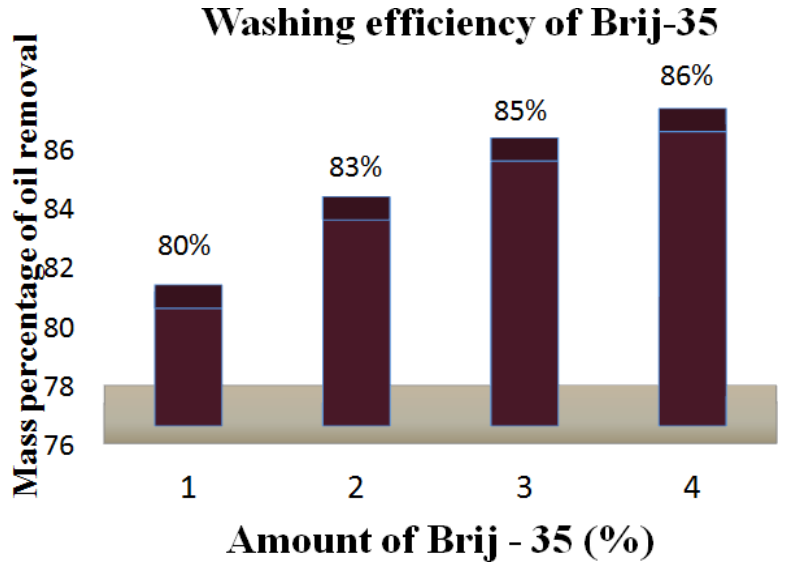

Fig. 5. Oil removal efficiency of Brij-35 at various concentration 1) $0.5 \%$ 2) $1 \%$ 3) $1.5 \%$ 4) $2.0 \%$

\section{SUMMARY AND CONCLUSION}

The global energy crisis is on high. The stringent environmental legislation led the industries to find the green alternates. In the present moment, the study of waste engine oil has become important, mainly contaminated soil remediation processes. The problem of soil and groundwater pollution was widely recognized in recent years. In this regard, determination of quality parameters of soil and waste engine oil maybe used as a vital need to uplift the quantum leap of used oil-recycling and understanding 
the soil remediation technology i.e. to remove waste lube oil from soil. This work will be useful in the identification of the extent of pollution of soil by the percolation of wastelube oil in long run.

\section{REFERENCES}

1. G Grzegorz Zajac, Joanna Sysiak-Barklowic, Tomasz Siowik, Andrzej Kuranic, Agnieszka Kaminskaz, "Original research designation of chosen heavy metals in used engine oils using the XRF method," Pol.J.Environ.studies, vol. 24, 2015, pp.2277-2283.

2. Munna Buttcharya,Dipa Biswasata, "A lab bench project for space craft autonomy enhancement of waste engine oil biodegradation by optimization of media using factorial design study,"Indian journal of biotecnology, vol. 13, 2014, pp. 193-300.

3. Arora K.R, "Soil mechanics and foundation engineering", $7^{\text {th }}$ edition.,A.K.Jain publishers, 2011, pp. 60-72.

4. A.J.T. Bhandari, D.C. Novakandand Dove, "Effect of soil washing on petroleum hydrocarbon distribution on sand surfaces," Journal of hazardous substance research, vol.2, 2000,pp.1-13.

5. U.Ghosh, J.S.Gillette, R.G. Luthy and R.N. Zare, "Microscale location, characterization and association of polycyclic aromatic hydrocarbons on harbor sediment particles," Environmental Science and Technology, vol.34, 2000, pp.1729-1736.

6. Shan-Tan Lu andIsaac R. Kaplan, "Characterization of Motor Lubricating Oils and Their Oil-Water Partition,"Journal Environmental Forensics, vol. 9, 2008, pp.295-309.

7. Riyanto1, B.Ramadhan, D.Wiyanti,“'Treatment of Waste Lubricating Oil by Chemical andAdsorption Process UsingButanol and Kaolin," IOP Conf. Series: Materials Science and Engineering, vol. 349, 2018, pp. 012054. DOI:10.1088/1757- 899X/349/1/012054.

8. Jing, Ye, Zhang, Yanli, "Pour Point Depressant for Waxy Crude Oil: A Mini-Review, Recent Innovations in Chemical Engineering Formerly Recent Patents on Chemical,vol.9, 2016, pp.78-87.

9. D.Geetha, R.Tyagi and N. Kumar,"Ability of Sugar Based Glucoside Surfactants for Removal of Petroleum Contaminants,"Journal of Surface Science and Technology, vol.31, 2015, pp.157-164.

\section{AUTHORS PROFILE}

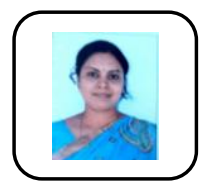

D.Geetha has completed M. Sc in Chemistry discipline from Bharathidasan University, M. Phil., from Annamalai University. She completed Ph. D from Jaypee University in 2016. She is currently working as an Assistant professor at Kalasalingam Academy of Research and Education from 2017 onwards. Her field of interest is bio surfactant. She has published 7 papers in reputed international journals.

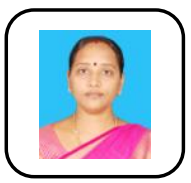

M.S.Revathy, has completed her Ph.D in Anna University in 2016. She has done M.Sc., M.Phil Physics in Mother Teresa Women's University, Kodaikanal. Currently working as Assistant Professor in Department of Physics, Kalasalingam Academy of Research and Education and her field of interests are thin films and green synthesis of nanomaterials. She has published 6 papers in international journals.

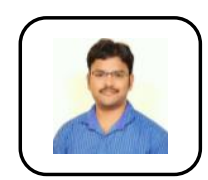

Gangadhara Angajala is working as an Assistant professor in Department of Chemistry at Kalasalingam Academy of Research and Education. $\mathrm{He}$ completed his under-graduation in B.Sc with triple major at Government Degree College for Men, Anantapur, Andhra Pradesh and his graduation with specialization in Pharmaceutical Chemistry at Vellore Institute of Technology, Tamil Nadu. He obtained his $\mathrm{Ph} . \mathrm{D}$ with specialization in Organic and Medicinal Chemistry from Vellore Institute of Technology. His research area includes synthesis of new quinoline scaffolds with hypoglycemic efficacy by using nanocatalysis.

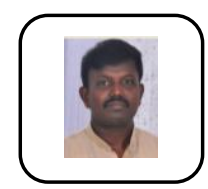

B. Sundaravel completed his Masters degree at VHNSN College affiliated to Madurai Kamaraj University. He was awarded Ph.D. degree in May 2014 by Anna University, Chennai, Tamil Nadu. Currently he is working as an Assistant Professor at Kalasalingam Academy of Research and Education, Krishnankoil, Tamil Nadu 